Thermomechanical Simulation and Processing of Steels, Simpro 08, eds S. K. Chaudhuri, B. K. Jha, S. Srikant, P. K. Maini, A. Deva, R. Datta, Allied Publishers Pvt. Ltd., Kolkata, India, (2008) pages 3-11.

\title{
Very Short and Very Long Heat-Treatments in the Processing of Steel
}

\author{
H. K. D. H. Bhadeshia \\ University of Cambridge, Materials Science and Metallurgy, U.K. \\ Graduate Institute of Ferrous Metallurgy, POSTECH, Republic of Korea \\ hkdb@cam.ac.uk, hkdb@postech.ac.kr
}

\begin{abstract}
It is conventionally assumed in the mass production of steels that the processing time must be reasonable and that the material must have uniform properties. The consequence is that short heat-treatments cannot be tolerated since the scale of engineered products may be so large that uniform temperatures cannot be achieved. Similarly, thermal treatments requiring several days or weeks are not considered practical because of productivity concerns.

In this paper I will show that these conservative ideas are a huge disadvantage to the creation of radically different steels whose manufacture could lead to an improvement in the quality of life. Indeed, such steels are capable of wiping out the competition from newcomers in the field of structural materials, such as the infamous carbon nanotubes and metal-matrix composites.
\end{abstract}

Keywords : steel, rapid heat treatment, long heat treatment, processing

\section{INTRODUCTION}

The purpose of this paper is to discuss the time needed to generate the desired microstructure in steel, and what should make the time acceptable or otherwise in the context of industrial practice. There are commercial processes being developed which take milliseconds to some ten days [1-3].

\section{QUALITATIVE FUNDAMENTALS}

We begin with a brief discussion of the atomic mechanisms which determine the time scales of phase transformations.

The microstructure is usually generated beginning with austenite as the parent phase. The transformation products can be classified into two categories, those which involve longrange diffusion and others in which the change in crystal structure is achieved by a macroscopically homogeneous deformation [4]. The former mechanism is known as reconstructive and the latter displacive (Fig. 1).

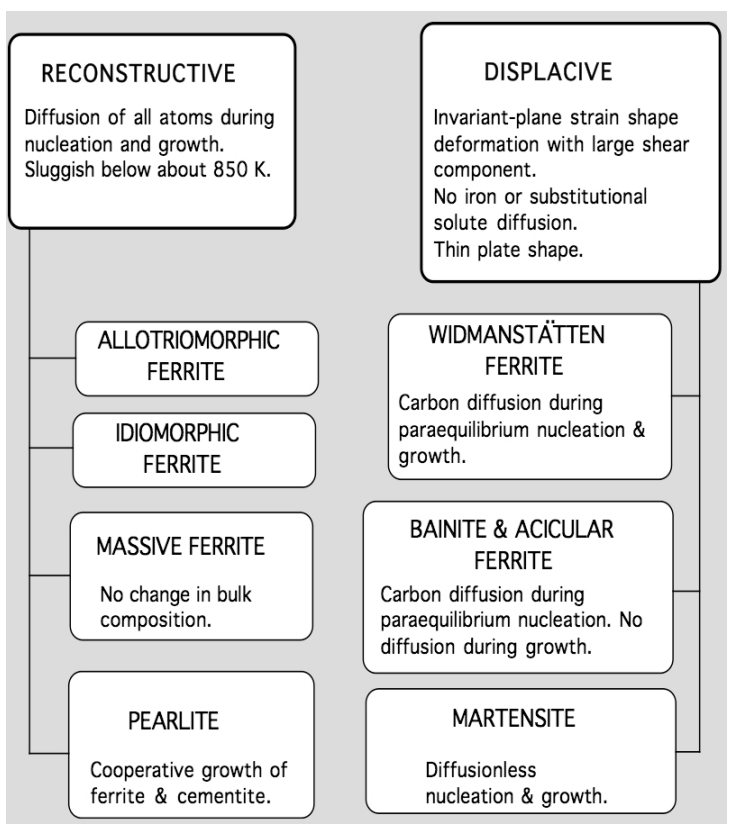

Fig. 1: Classification of transformation products as a function of the atomic mechanism of transformation.

The formation of allotriomorphic, idiomorphic and massive ferrite, and of pearlite, requires the diffusion of all elements including iron $[5,6]$. The movement of iron or substitutional 
Thermomechanical Simulation and Processing of Steels, Simpro 08, eds S. K. Chaudhuri, B. K. Jha, S. Srikant, P. K. Maini, A. Deva, R. Datta, Allied Publishers Pvt. Ltd., Kolkata, India, (2008) pages 3-11.

solutes occurs by a vacancy mechanism and hence can be slow at low temperatures. As illustrated in Fig. 2 , the scale of the microstructure must diminish as the transformation temperature is reduced [7], which is an advantage since both strength and toughness are improved when the microstructure is refined.

However, it is also evident that the time required to achieve a given scale increases dramatically as the temperature is reduced, making it impractical to design structures which are fine by reducing the transformation temperature. To summarise, rapid heat treatments are impossible with reconstructive transformations if the ultimate goal is to achieve fine microstructures.

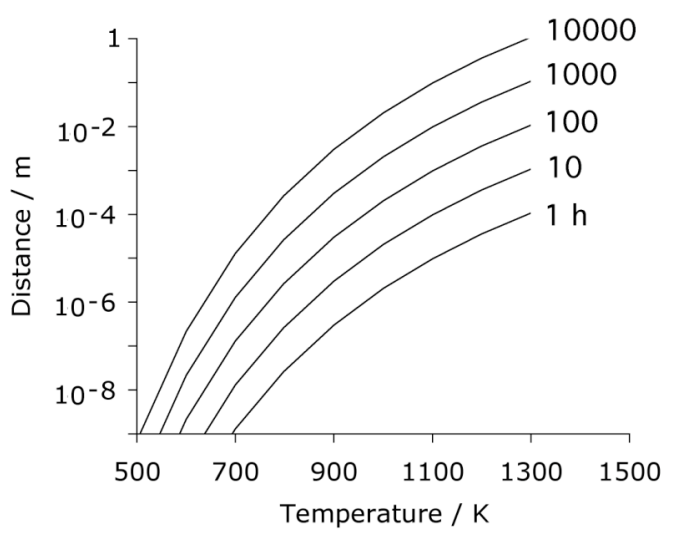

Fig. 2: Diffusion distance of an iron atom in austenite as a function of temperature and time. The estimate is made using $2 \sqrt{D t}$ where $D$ is the diffusion coefficient of iron in austenite [8] and $t$ is the time.

The second class of transformations does not require the diffusion of atoms (Fig. 1) in substitutional sites and hence can be much more rapid. The change in crystal structure is achieved by a physical deformation which can be detected experimentally as a permanent strain. Interstital atoms may in certain cases be mobile, but their order or disorder does not influence the nature of the deformation.

The motion of the interface during displacive transformation is in principle only limited by the speed of sound in the metal, some thousands of $\mathrm{m} \mathrm{s}^{-1}$, which is in contrast to the highest solidification velocities in pure nickel at some $80 \mathrm{~m} \mathrm{~s}^{-1}$. In practice the growth velocity of, for example martensite, may not get as high as the speed of sound in the metal, being limited by damping due to the emission of dislocations or other dissipating phenomena.

Diffusion of solute, whether this is substitutional or interstitial must always slow the rate of transformation. Diffusional transformations will therefore tend to be faster in pure materials.

Rapid transformation of austenite, involving diffusion, can therefore only occur at elevated temperatures. There is one exception to this, as described below.

Many commercial processes cause the steel to revert into the austenitic condition. The transformation of lowtemperature ferrite into hightemperature austenite differs from the case where the latter transforms during cooling. Transformation during cooling follows C-curve kinetics in which the overall transformation rate goes through a maximum as a function of the undercooling below the equilibrium temperature. This is because diffusion coefficients decrease but the magnitude of the driving force $|\Delta G|$ increases as the temperature is reduced. In contrast, both the diffusivity and driving force for austenite formation increase as a ferritic microstructure is superheated. The rate of diffusion-controlled transformation increases indefinitely as the temperature is raised, Fig. 3 [9].

Since the transformation rate during heating accelerates indefinitely at the temperature is raised, the transformation times tend towards zero. One consequence of this is that in many steel diffusion is unavoidable during heating, so incredibly high heating rates are needed in order to induce displacive transformation during heating. Austenite formation 
can be induced in incredibly small time periods using laser heating [10-13].

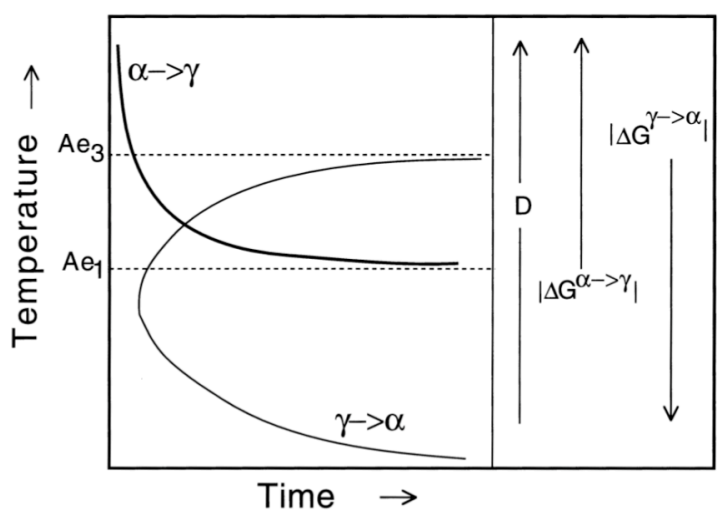

Fig. 3: The TTT (time temperature transformation) curves for the $\gamma \rightarrow \alpha$ reaction, and for the $\alpha \rightarrow \gamma$ reverse transformation. The $\mathrm{Ae}_{3}$ and $\mathrm{Ae}_{1}$ temperatures represent the temperatures at which austenite formation begins and ends respectively, under equilibrium heating conditions.

\section{LONG TRANSFORMATION TIMES}

Slow reaction rates can be an advantage when dealing with strong steels which are destined for critical applications such as shafts. This is because the austenite does not need to be cooled rapidly, thus avoiding the development of quench stresses $[9,10]$.

Temperature gradients naturally occur in large samples when they are cooling from the austenite phase field to an isothermal transformation temperature. The transformation then does not occur at the same instant in all locations within the component being heat-treated. A slow reaction rate would ensure that the steel reaches a uniform temperature before transformation begins, thus making the material resistant to the development of internal stresses due to a heterogeneous distribution of temperature.

Long transformation times also permit the manufacture of components which are large in all three dimensions; this is why processes such as the manufacture of metallic glasses by rapid quenching are limited to thin ribbons.
A slow rate can be achieved either by increasing the hardenability of the steel or by transforming at a temperature where solid-state transformations become sluggish. We present here an example where both hardenability and suppressedtransformation temperatures are exploited in order to reduce the rate of transformation.

It would be nice to have a strong material which can be used for making components which are large in all their dimensions, and which does not require mechanical processing or rapid cooling to reach the desired properties. The following conditions are required to achieve this:

- The material must not rely on perfection to achieve its properties. Strength can be generated by incorporating a large number density of defects such as grain boundaries and dislocations, but the defects must not be introduced by deformation if the shape of the material is not to be limited.

- Defects can be introduced by phase transformation, but to disperse them on a sufficiently fine scale requires the phase change to occur at large undercoolings (large free energy changes).

Transformation at low temperatures also has the advantage that the microstructure becomes refined.

- A strong material must be able to fail in a safe manner. It should be tough.

- Recalescence limits the undercooling that can be achieved. Therefore, the product phase must be such that it has a small latent heat of formation and grows at a rate which allows the ready dissipation of heat. 
Recent discoveries have shown that carbide-free bainite can satisfy these criteria [2]. Bainite and martensite are generated from austenite without diffusion by a displacive mechanism. Not only does this lead to solutetrapping but also a huge strain energy term $[14,15]$, both of which reduce the heat of transformation. The growth of individual plates in both of these transformations is fast, but unlike martensite, the overall rate of reaction is much smaller for bainite. This is because the transformation propagates by a sub-unit mechanism in which the rate is controlled by nucleation rather than growth $[16,17]$. This mitigates recalescence [7].

The theory of the bainite transformation allows the estimation of the lowest temperature at which bainite can be induced to grow. Such calculations are illustrated in Fig. 4a, which shows how the bainite-start $\left(B_{S}\right)$ and martensite-start $\left(\mathrm{M}_{\mathrm{S}}\right)$ temperatures vary as a function of the carbon concentration, in a particular alloy system. There is in principle no lower limit to the temperature at which bainite can be generated. On the other hand, the rate at which bainite forms slows down dramatically as the transformation temperature is reduced (Fig. 4b). It may take hundreds or thousands of years to generate bainite at room temperature. For practical purposes, the carbon concentration has to be limited to about $1 \mathrm{wt} \%$ for the case illustrated.

An alloy has been designed in this way, with the approximate composition Fe-1C-1.5Si-1.9Mn-0.25Mo-1.3Cr$0.1 \mathrm{~V}$ wt $\%$, which on transformation at $200^{\circ} \mathrm{C}$, leads to bainite plates which are only $20-40 \mathrm{~nm}$ thick. The slender plates of bainite are dispersed in stable carbon-enriched austenite which, with its face-centred cubic lattice, buffers the propagation of cracks (Fig. 5).

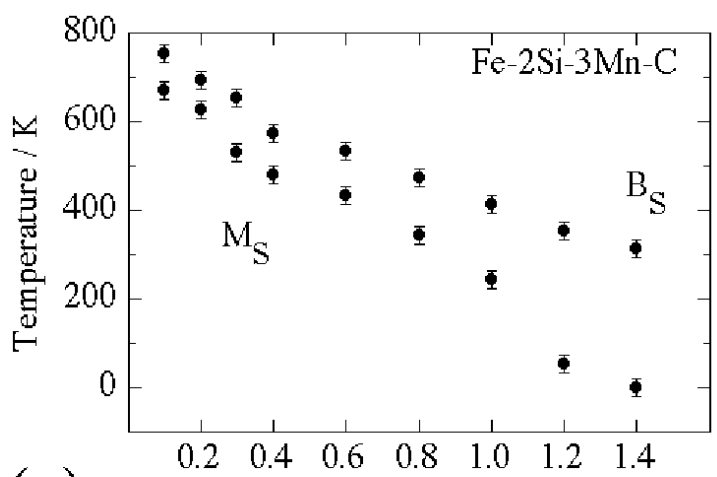

(a) Carbon $/ \mathrm{wt} \%$

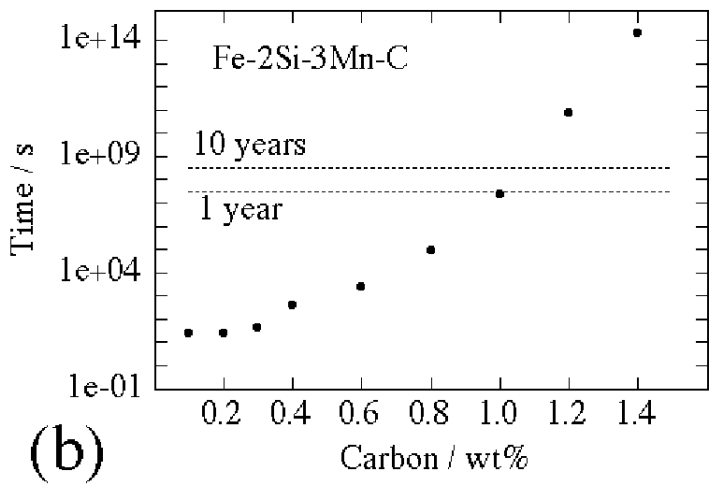

Fig. 4: (a) Calculated transformation start temperatures in $\mathrm{Fe}-2 \mathrm{Si}-3 \mathrm{Mn}$ wt\% steel as a function of the carbon concentration. (b) The calculated time required to initiate bainite at the $\mathrm{B}_{\mathrm{S}}$ temperature.

The bainite obtained by transformation at very low temperatures is the hardest ever (700 HV, $2500 \mathrm{MPa})$, has considerable ductility, is tough (30-40 $\mathrm{MPa} \mathrm{m}^{1 / 2}$ ) and does not require mechanical processing or rapid cooling. The steel after heat-treatment therefore does not have long--range residual stresses, it is very cheap to produce and has uniform properties in very large sections. In effect, the hard bainite has achieved all of the essential objectives of structural nanomaterials which are the subject of so much research, but in large dimensions. 

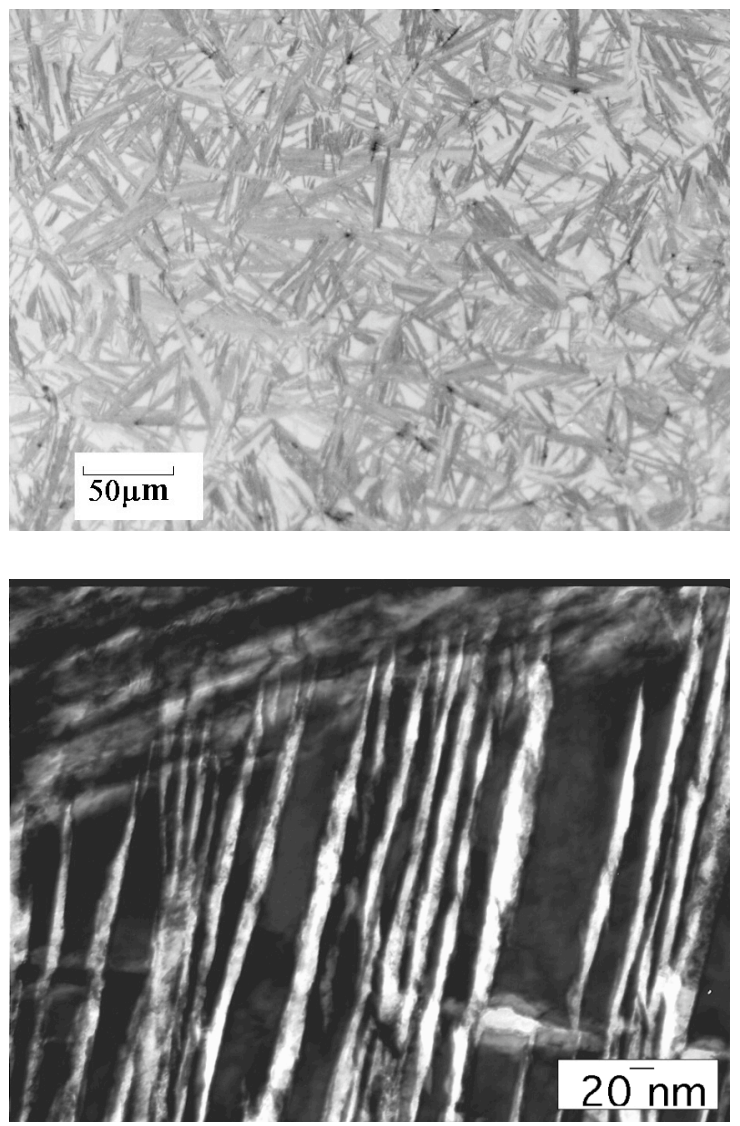

Fig. 5: Bainite obtained by transformation at $200^{\circ} \mathrm{C}$. (a) Optical micrograph. (b) Transmission electron micrograph (Mateo and Bhadeshia).

\section{SHORT TRANSFORMATION TIMES}

Rapid transformation is conducive to high productivity and can be exploited to minimise the alloy content of the steel. Hence the tremendous success of the process of accelerated cooling which is used in the manufacture of large quantities of steel for structural engineering $[18,19]$.

A major advantage of using a leanly alloyed steel in combination with rapid cooling is to mitigate the effects of solidification-induced chemical segregation.

Control-rolled steels are cast continuously so they contain pronounced chemical segregation along the mid-thickness of the plate. For example, the manganese concentration at the centre can reach twice the average value. Ferrite naturally forms first in the manganesedepleted regions; the carbon partitioned as the ferrite grows ends up in the manganese-rich regions of austenite. This exaggerates the hardenability of the manganese-rich regions which transform into bands of hard microstructure.

These bands are susceptible to hydrogen cracking. Hydrogen can be infused into the steel through corrosion reactions or other phenomena. An advantage of the accelerated cooled steels is that they are more microstructurally homogeneous (Fig. 6); this is because the ferrite and bainite form at a larger undercooling during accelerated cooling (Fig. 7), so transformation occurs everywhere, even in the manganese-rich regions. The gross banding characteristic of ferrite-pearlite microstructures is therefore minimised or avoided altogether $[18,20]$. The resulting lower hardness in the segregated zone makes the steel less susceptible to hydrogen-induced cracking.

Cracking ceases to be a problem because the hardness in all regions becomes less than about $250 \mathrm{HV}$ $[18,19]$.

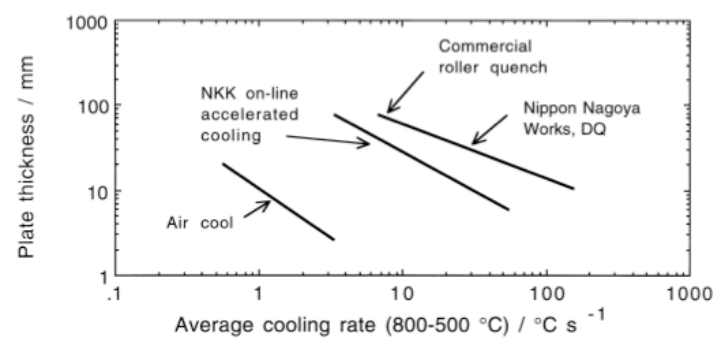

Fig. 7: Cooling rates that can typically be achieved in commercial circumstances.

The general conclusion is that microstructures which are homogeneous, and which contain less carbon, are less susceptible to both hydrogen-induced cracking and sulphide stress-corrosion cracking. In low-carbon pipeline steels, a bainitic microstructure is found to be more resistant to these problems than one containing allotriomorphic ferrite [21]. 


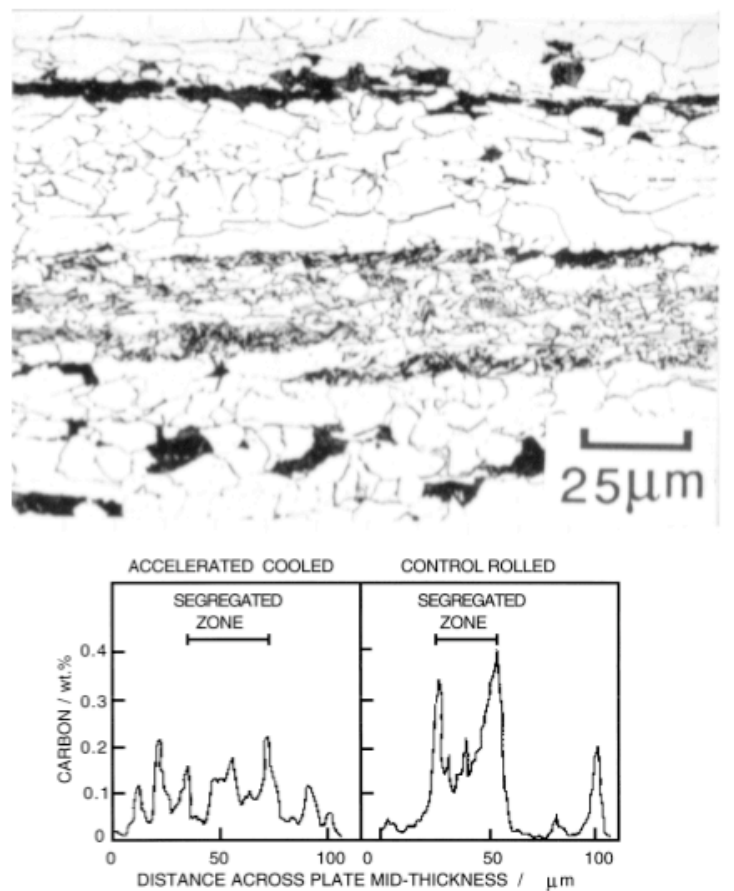

Fig. 6: (a) A light micrograph illustrating the effect of chemical segregation along the midthickness of heavy gauge plate. (b) Distribution of carbon concentration in the segregated zone for conventional controlrolled and rapidly cooled steel plates $[18,19]$.

\section{"FLASH PROCESSING"}

In recent work, Cola Jr. [1] has claimed to have produced bainitic steel in tens of milliseconds using a process designated flash processing.

In this, a strip shaped sample of steel of typical composition 0.2C-0.3Si$0.7 \mathrm{Mn}-0.5 \mathrm{Cr}-0.5 \mathrm{Ni}-0.2 \mathrm{Mo}-0.2 \mathrm{Cu}$ wt $\%$ is passed through an oxygen-propane fired system which applies heat directly to the steel strip as it passes through the equipment. The rapidly heated $1.5 \mathrm{~mm}$ thick strip is then directly water queched.

This is a high productivity process which results in steel with a yield strength in the range $786-1269 \mathrm{MPa}$ and elongation in the range $3-7 \%$, depending largely on the chemical composition. There may be significant applications of the process in the manufacture of components in the automobile industry, particularly those which are currently hot-press formed.

\section{ACCELERATING REACTIONS}

All of the major transformations in steels, including martensite, involve the stages of nucleation and growth. Anything which enhances the nucleation rate will accelerate transformation, and the most common way of doing this is by refining the austenite grain size. The number density of nucleation sites increases with inversely with the austenite grain size.

A further method is to increase the amount of austenite grain boundary area per unit volume by pancaking the austenite; the increase in grain surface can be predicted quantitatively [22].

If the austenite is left in the deformed state then other defects such as shear bands and dislocations may also contribute to the nucleation rate. However, such defects can, in the case of displacive transformations, retard kinetics by a phenomenon known as mechanical stabilisation [23].

Another technique is to increase the magnitude of the free energy change accompanying the transformation of austenite. This can be done by reducing elements such as manganese or carbon, or by adding cobalt or aluminium, both of which have the desired effect.

Fig. 7 illustrates how low-temperature bainite, which normally takes many days in order to achieve the required degree of transformation, has been accelerated by alloying with $\mathrm{Co}$ and $\mathrm{Al}$; detailed compositions (wt\%) below:

\begin{tabular}{|c|cccccccc|}
\hline Alloy & C & $\mathrm{Si}$ & $\mathrm{Mn}$ & $\mathrm{Mo}$ & $\mathrm{Cr}$ & $\mathrm{V}$ & $\mathrm{Co}$ & $\mathrm{Al}$ \\
\hline 1 & 0.98 & 1.46 & 1.89 & 0.26 & 1.26 & 0.09 & & \\
2 & 0.83 & 1.57 & 1.98 & 0.24 & 1.02 & & 1.54 & \\
3 & 0.78 & 1.49 & 1.95 & 0.24 & 0.97 & & 1.60 & 0.99 \\
\hline
\end{tabular}



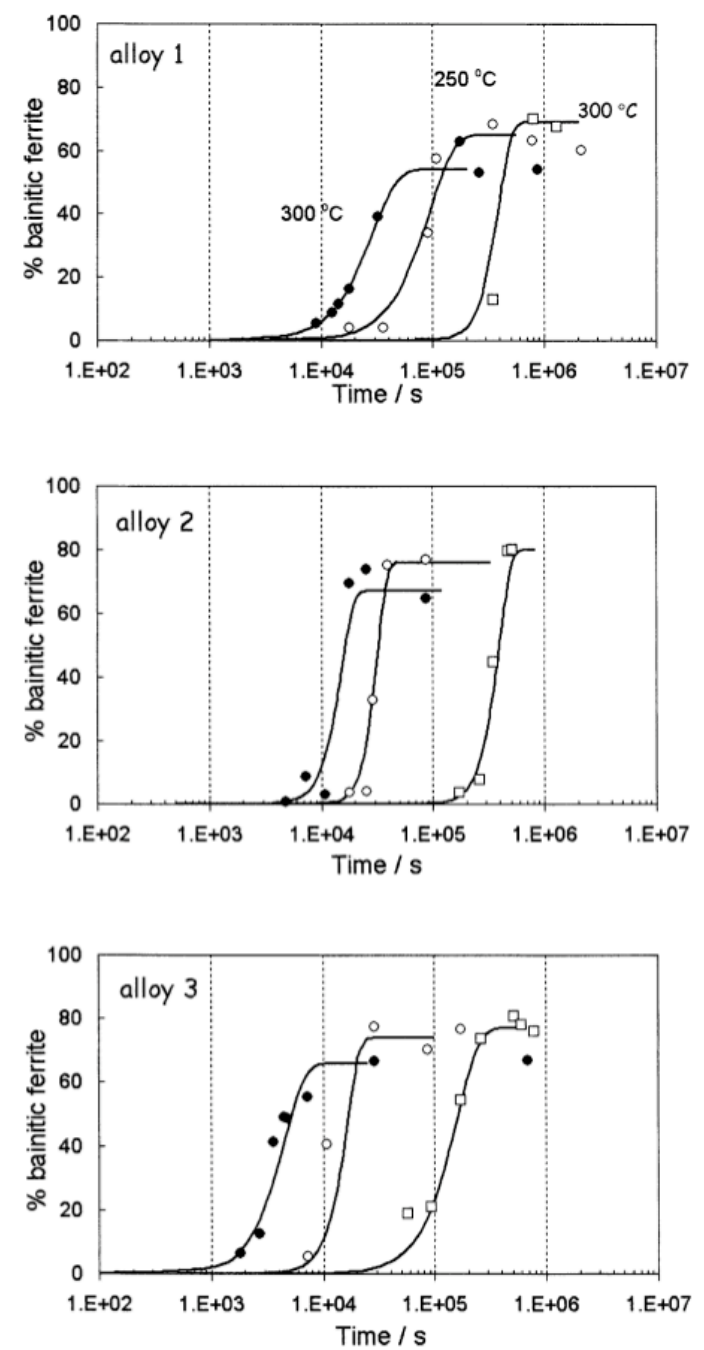

Fig. 7: Isothermal transformation curves. The filled circles, open circles and open squares correspond to the transformation temperatures of 300,250 and $200^{\circ} \mathrm{C}$ respectively [24].

\section{YEAR EXPERIMENT}

An examination of Fig. 4 shows that it should be possible to obtain bainite at room temperature, but that the transformation time would be approximately 100 years. An appropriate alloy was made in 2004 to test this theory. Its starting microstructure, illustrated in Fig. 8 , is austenite and carbides, but no bainite. Two samples have been archived, one at Cambridge University and the other at the Science Museum in London. The samples are sealed in quartz tubes containing pure argon. The tubes will be broken in 2104 to see whether bainite has formed and to conduct detailed characterisation. The samples have been polished to a mirror finish so any phase change will be evident in the mean time, through surface rumples caused by transformation.

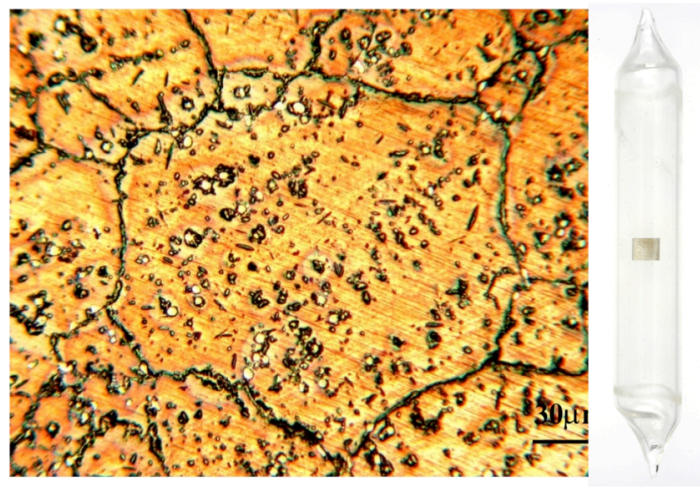

Fe-1.75C-Si-Mn wt\%

Chatterjee \& Bhadeshia, 2004

Fig. 8: Experiment started in 2004, to stimulate bainite to form by 2104 .

\section{SUMMARY}

Transformation times of tens of milliseconds to ten days are no longer regarded as impossible by industry. Indeed, there are leading-edge products under development and at an advanced stage of application where these transformation times are deemed acceptable.

This is because the steels resulting from these unusual heat treatments also have interesting properties.

\section{ACKNOWLEDGEMENTS}

I am grateful to conference organisers for this wonderful meeting and to the University of Cambridge and POSTECH for the provision of laboratory facilities through the good offices of Professor A. L. Greer and Professor H.-G. Lee.

\section{REFERENCES}

1. G. M. Cola, "Properties of bainite nucleated by water quenching in $80 \mathrm{~ms}$ ", Proc. of the 1st Int. Symp. on Steel Science (IS-2007), the Iron and Steel Institute of Japan, editors T. Furuhara and $\mathrm{K}$.

Tsuzaki, 2007, 187-190. 
Thermomechanical Simulation and Processing of Steels, Simpro 08, eds S. K. Chaudhuri, B. K. Jha, S. Srikant, P. K. Maini, A. Deva, R. Datta, Allied Publishers Pvt. Ltd., Kolkata, India, (2008) pages 3-11.

2. F. G. Caballero and H. K. D. H. Bhadeshia, "Very strong bainite" Current Opinion in Solid State and Materials Science, 8 (2004) 251257.

3. H. K. D. H. Bhadeshia, "52nd Hatfield memorial lecture: large chunks of very strong steel" Materials Science and Technology, 21 (2005) 1293-1302.

4. H. K. D. H. Bhadeshia and J. W. Christian, "The bainite transformation in steels", Metallurgical Transactions A, 21A, (1990) 767-797.

5. H. K. D. H. Bhadeshia, "Diffusional formation of ferrite in iron and its alloys" Progress in Materials Science, 29 (1985) 321-386.

6. H. K. D. H. Bhadeshia, "Mobility of the transformation interface", Journal de Physique, 43 (1982) C4-435-441.

7. T. Yokota, C. Garcia-Mateo and H. K. D. H. Bhadeshia, "Formation of Nanostructured Steels by Phase Transformation", Scripta Materialia, 51 (2004) 767-770.

8. J. Fridberg, L.-E. Torndahl and M. Hillert, "Diffusion in iron, Jernkontorets Ann., 153 (1969) 263-276.

9. J. R. Yang and H. K. D. H. Bhadeshia, "Continuous heating transformation of bainite to austenite, Materials Science and Engineering, A131 (1991) 99-113.

9. P. J. Withers and H. K. D. H. Bhadeshia, "Residual stress nature and origins, Materials Science and Technology, 17 (2001) 366-375.

10. T. Reti, G. Bagyinszki, I. Felde, B. Vero and T. Bell, "Prediction of asquenched hardness after rapid austenitisation and cooling of surface hardened steels, Computational Materials Science, 15 (1999) 101-112.

11. R. C. Reed, Z. Shen, T. Akbay and J. M. Robinson, "Laser pulse heat treatment: application to reaustenitisation from ferrite/cementite mixtures", Materials Science and Engineering, A232 (1997) 140-149.

12. M. Y. Wei and C. Chen, "Predicting case depth in tempered steels hardened via laser processing, Materials Science and Technology, 10 (1994) 69-73.

13. J. R. Bradley and S. Kim, "Laser transformation hardening of a high purity $\mathrm{Fe}-\mathrm{C}-\mathrm{Cr}$ alloy", Scripta Metallurgica, 23 (1989) 131-136.

14. E. Swallow and H. K. D. H. Bhadeshia, "High resolution observations of the displacements caused by bainitic transformation", Materials Science and Technology, 12 (1996) 121-125.

15. J. W. Christian, "Thermodynamics and kinetics of martensite", Proc. ICOMAT '79, MIT Press (1979) 220-234.

16. R. F. Hehemann, "The bainite transformations", Phase Transformations, ASM (1970) 397432.

17. H. Matsuda and H. K. D. H. Bhadeshia, "Kinetics of the bainite transformation", Proc. Roy. Soc. A 460 (2004) 1710-1722.

18. H. Tamehiro, T. Takeda, S. Matsuda, K. Yamamoto and N. Okumura, "Effect of accelerated cooling after controlled rolling on hydrogen induced cracking resistance of line pipe steels", ISIJ International 25 (1985) 982-988.

19. H. Tamehiro, N. Yamada and $\mathrm{H}$. Matsuda, "Effect of 
Thermomechanical Simulation and Processing of Steels, Simpro 08, eds S. K. Chaudhuri, B. K. Jha, S. Srikant,

P. K. Maini, A. Deva, R. Datta, Allied Publishers Pvt. Ltd., Kolkata, India, (2008) pages 3-11.

thermomechanical control process

on the properties of high strength

low alloy steel", Trans. ISIJ 25

(1985) 54-61.

20. M. K. Graf, H. G. Hillenbrand and P. A. Peters, "Accelerated cooling of plate for high-strength largediameter pipe", Accelerated Cooling of Steel, ed. P D Southwick, TMS AIME, (1985) 165-180

21. M. C. Zhao, Y. Y. Shan, F. R. Xiao, K.Yang and Y. H. Li, "Pipeline steel X65 X70 X80 acicular bainite ultrafine sulphide stress corrosion hydrogen", Materials Letters, 57 (2002) 141-145.

22. Q. Zhu, C. M. Sellars and H. K. D. $H$. Bhadeshia, "Quantitative metallography of deformed grains", Materials Science and Technology, 23 (2007) 757-766.

23. S. Chatterjee, H. S. Wang, J. R. Yang and H. K. D. H. Bhadeshia, "Mechanical stabilisation of austenite", Materials Science and Technology, 22 (2006) 641-644.

24. C. Garcia-Mateo, F. G. Caballero and H. K. D. H. Bhadeshia, "Acceleration of low-temperature bainite", ISIJ International 43 (2003) 1821-1825. 